\title{
Impact of protein energy wasting status on survival among Afro-Caribbean hemodialysis patients: a 3-year prospective study
}

\author{
Lydia Foucan ${ }^{1,2^{*}}$, Henri Merault ${ }^{1,3}$, Fritz-Line Velayoudom-Cephise ${ }^{2}$, Laurent Larifla ${ }^{2}$, Cosmin Alecu ${ }^{2}$ \\ and Jacques Ducros ${ }^{1,3}$
}

*Correspondence: Ifoucan@ yahoo.fr

${ }^{2}$ Département de Santé Publique, Equipe de recherche Epidémiologie Clinique et Médecine ECM/ LAMIA, EA 4540, Centre Hospitalier Universitaire, Université des Antilles et de la Guyane, CHU de Pointeà-Pitre, 97159 Pointe-à-Pitre, Guadeloupe, France

Full list of author information is available at the end of the article

\begin{abstract}
Background: We assessed the prognostic value of protein-energy wasting (PEW) on mortality in Afro-Caribbean MHD patients and analysed how diabetes, cardiovascular disease (CVD) and inflammation modified the predictive power of a severe wasting state.

Method: A 3-year prospective study was conducted in 216 patients from December 2011. We used four criteria from the nomenclature for PEW proposed by the International Society of Renal Nutrition and Metabolism in 2008: serum albumin $38 \mathrm{~g} / \mathrm{L}$, body mass index $(\mathrm{BMI}) \leq 23 \mathrm{~kg} / \mathrm{m}^{2}$, serum creatinine $\leq 818 \mu \mathrm{mol} / \mathrm{L}$ and protein intake assessed by $\mathrm{nPCR} \leq 0.8 \mathrm{~g} / \mathrm{kg} /$ day. PEW status was categorized according the number of criteria. Cox regression analyses were used.
\end{abstract}

Results: Forty deaths (18.5 \%) occurred, $97.5 \%$ with a CV cause. Deaths were distributed as follows: $7.4 \%$ in normal nutritional status, $13.2 \%$ in slight wasting (1 PEW criterion), $28 \%$ in moderate wasting (2 criteria) and $50 \%$ in severe wasting (3-4 criteria). Among the PEW markers, low serum albumin (HR 3.18; P = 0.001) and low BMI ( HR 1.97; $P=0.034$ ) were the most significant predictors of death. Among the PEW status categories, moderate wasting (HR 3.43; $P=0.021)$ and severe wasting (HR 6.59; $P=0.001)$ were significant predictors of death. Diabetes, CVD, and inflammation were all additives in predicting death in association with severe wasting with a strongest $H R$ (7.76; $P<0.001)$ for diabetic patients.

Conclusions: The nomenclature for PEW predicts mortality in our Afro-Caribbean MHD patients and help to identify patients at risk of severe wasting to provide adequate nutritional support.

Keywords: Afro-Caribbean patients, Body mass index, Hemodialysis, Mortality, Protein-energy wasting, Serum albumin

\section{Background}

Individuals from French oversea territories experience a higher incidence of end stage renal disease (ESDR) compared with continental French individuals: with 246/million inhabitants in Guadeloupe, a French Caribbean island, vs 149/million inhabitants in continental France (Briancon et al. 2011). High frequencies of traditional risk factors, which affect survival, were also reported in this population having a majority of patients

(c) 2015 Foucan et al. This article is distributed under the terms of the Creative Commons Attribution 4.0 International License (http://creativecommons.org/licenses/by/4.0/), which permits unrestricted use, distribution, and reproduction in any medium provided you give appropriate credit to the original author(s) and the source, provide a link to the Creative Commons license, and indicate if changes were made. 
of African ancestry (Foucan et al. 2000, 2012). In patients on maintenance hemodialysis (MHD), cardiovascular disease, diabetes mellitus and inflammation contribute to the high death rate (Goodkin et al. 2004). Uremic malnutrition, also called, protein energy wasting (PEW), corresponding to a decrease in energy and body protein, was consistently associated with mortality in different populations (Kovesdy and Kalantar-Zadeh 2009; Noori et al. 2011; Streja et al. 2011) and appears as the strongest risk factor for adverse outcome and death (Kovesdy and Kalantar-Zadeh 2009).

In a nomenclature for PEW proposed by the International Society of Renal Nutrition and Metabolism (Fouque et al. 2008), several parameters among four established categories (biochemical criteria; body mass and composition, muscle mass and dietary intakes) are indicative of PEW in individuals with kidney disease. Ethnic disparities were reported for the PEW biochemical markers (Noori et al. 2011) but also for muscle mass (Gallagher et al. 1985; Kramer et al. 2008). Recently, a score derived from this nomenclature predicted survival in the European ARNOS prospective dialysis cohort but, the need to evaluate the predictive ability of this PEW classification for mortality in nonWestern populations was highlighted (Moreau-Gaudry et al. 2014).

In the present study we assessed the prognostic value of PEW on mortality in Afro Caribbean MHD patients and analyzed how several factors of interest modified the predictive power of a severe wasting state.

\section{Subjects and methods}

\section{Patient population}

In the present study, we included patients who underwent MHD treatment for more than 3 months and evaluated in December 2011 in the AUDRA centre (one of the dialysis facilities in the island of Guadeloupe, France). They were prospectively followed up from December 31, 2011, to December 31, 2014.

Standard dialysis treatment consisted of three weekly sessions using bicarbonate buffer and synthetic high flux membrane. Weekly dialysis time was $12 \mathrm{~h}$ in $83 \%$ of patients. Dialysis dose delivery was estimated from the urea Kt/V (urea clearance over time).

\section{Data collection}

Demographic and clinical data such as age, sex, dialysis vintage (time on HD), anthropometric parameters, cardiovascular risk factors, history of cardio vascular events and nutritional supplementation were recorded. Body mass index (BMI) in $\mathrm{kg} / \mathrm{m}^{2}$ was calculated as dry weight divided by height squared.

Dialysis vintage was defined as the duration of time between the first day of HD treatment and December 31, 2011. Interdialytic weight gain (IDWG) was calculated as the difference between predialysis body weight and preceding postdialysis body weight during the month preceding the start of the study (December 2011) and the month preceding the end of follow-up for each patient. The mean value of 12 IDWG during the month was taken into account.

Dates and primary causes of death were recorded. The survival time was defined as the number of days between December 31, 2011 and the date of death or the date of censoring due to loss to follow-up (transfer to another dialysis centre or kidney transplantation) or the end of the follow-up at December 31, 2014. 


\section{Laboratory measures}

All laboratory values were measured by automated and standardized methods. Predialysis samples were collected for serum albumin, transthyretin, creatinine and highly sensitive C-reactive protein (hsCRP) measurements. Serum albumin, transthyretin and creatinine concentrations were determined.

The normalized protein catabolic rate (nPCR) (Aparicio et al. 1999; Daugirdas 1989) was used to assess the dietary protein intake with the following formula.

$$
\mathrm{nPCR}=(0.0136 \times \mathrm{F})+0.251 \text { in } \mathrm{g} / \mathrm{kg} \text { per day }
$$

where $\mathrm{F}$ is equal to $\mathrm{Kt} / \mathrm{V} \times($ [predialysis $\mathrm{BUN}+$ postdialysis $\mathrm{BUN}] / 2)$.

\section{Definition of clinical factors and events}

$P E W$ One component in each of the four categories of the wasting syndrome (Fouque et al. 2008) were retained: serum albumin $\leq 38 \mathrm{~g} / \mathrm{L}, \mathrm{BMI} \leq 23 \mathrm{~kg} / \mathrm{m}^{2}, \mathrm{SCr} \leq 25$ th percentile $\left(\mu \mathrm{mol} / \mathrm{L} / \mathrm{m}^{2}\right)$ and $\mathrm{nPCR} \leq 0.8 \mathrm{~g} / \mathrm{kg} /$ day. Slight wasting was defined when one criteria for PEW was present, moderate wasting when two criteria for PEW was present, and severe wasting in presence of three or four criteria for PEW.

- Inflammation was defined as a serum concentration of CRP of $>5 \mathrm{mg} / \mathrm{L}$

- Cardiovascular disease (CVD) was defined as pre-existing coronary artery disease or stroke. Pre-existing CV complications included, coronary event and stroke occurred before December 2011.

- Weight loss: was defined as $-5 \%$ over 3 months (Fouque et al. 2008).

Outcome data considered as death of all causes were obtained from medical record.

\section{Statistical methods}

Data are presented as percentages for categorical variables and as means \pm standard deviations (SD) for continuous variables. Statistical methods included the $\chi^{2}$, ANCOVA adjusted for age and sex.

Multivariate Cox proportional hazards models were performed to analyze survival and to study the associations of PEW markers and PEW status as independent variables with death of all causes. The PEW markers (serum albumin $\leq 38 \mathrm{~g} / \mathrm{L}, \mathrm{BMI} \leq 23 \mathrm{~kg} / \mathrm{m}^{2}$, $\mathrm{SCr} \leq 25$ th percentile in $\mu \mathrm{mol} / \mathrm{L}$ and $\mathrm{nPCR} \leq 0.8 \mathrm{~g} / \mathrm{kg} /$ day) and the PEW status (normal nutritional status, slight wasting, moderate wasting and severe wasting) were studied separately. The variables of adjustment were: age ( $<60$ or $\geq 60$ years), gender, dialysis vintage ( $<5$ or $\geq 5$ years), diabetes, pre-existing CVD and hsCRP ( $<5$ or $\geq 5 \mathrm{mg} / \mathrm{L})$.

We also explored the potential additive association between severe wasting and three other risk factors of death in HD patients (pre existing CVD, diabetes and inflammation).

Hazard ratios (HR) and $95 \%$ confidence interval (95\% CI) were provided. Significance was set at $\mathrm{P}<0.05$.

Statistical analyses were performed by using IBM-SPSS statistical software package version 21 (IBM, Armonk, NY, USA). 


\section{Results}

Overall, 216 patients were included in the analysis. The population was $56.5 \%$ male. All the patients had diuresis lower than $500 \mathrm{~mL} /$ day (i.e. no residual renal function). The relevant demographic, clinical, and laboratory data of the study patients are presented in Additional file 1: Table S1. Mean age at baseline was 60 years and median dialysis vintage was 6.4 years. Average $\mathrm{Kt} / \mathrm{V}$ was 1.31. Inflammation (CRP $>5 \mathrm{mg} / \mathrm{L}$ ) was found in $42.6 \%$ of patients.

The major comorbidities were hypertension (91\%), diabetes (37\%), obesity (17\%) and previous cardiovascular events (13.9\%). Inflammation (CRP $>5 \mathrm{mg} / \mathrm{L}$ ) was found in $42.6 \%$ of the patients.

Diabetic patients were more likely to have previous CVD than non-diabetic patients ( 23.5 vs. $8.1 \%$; $\mathrm{P}=0.002$ ).

Thirty patients were censored: 22 following kidney transplantation and 8 following transfer to another HD centre.

Forty deaths (18.5\%) occurred during the 3-year follow up, $97.5 \%$ with a CV cause and $2.5 \%$ with a non $\mathrm{CV}$ cause.

Deaths were distributed as follow: 5/65 (7.7 \%) in normal nutritional status, 10/80 $(12.5 \%)$ in slight wasting, $14 / 50(28 \%)$ in moderate wasting and 10/20 (50 \%) in severe wasting.

The causes of death were stroke (37.5\%), myocardial infarction (32.5\%), acute mesenteric ischemia (15\%), cardiac insufficiency (12.5\%) and sepsis $(2.5 \%)$.

In comparing at baseline clinical, and laboratory data of patients who died and those who survived, at baseline, patients who died were more likely to be older $(\mathrm{P}<0.001)$, to have diabetes $(\mathrm{P}<0.001)$, a weight loss over 3 months $(\mathrm{P}<0.001)$, previous cardiovascular disease $(\mathrm{P}=0.006)$ and to have lower serum albumin $(\mathrm{P}<0.001)$, lower serum creatinine values $(P=0.013)$ and higher frequency of inflammation $(P=0.014)$ (Additional file 1: Table S1).

Additional file 1: Table S2 details the frequencies of the nutritional markers and the nutritional status at baseline. Significant differences were noted between patients who died and who survived for the biochemical criteria $(P<0.001)$, body mass $(P=0.025)$ and for the surrogate of muscle mass $(P=0.015)$ but not for dietary intakes $(P=0.114)$. A normal nutritional status was more frequently noted in those who survived $(P=0.007)$ whereas moderate or severe wasting were more frequent in patients who died $(\mathrm{P}=0.022$ and $\mathrm{P}<0.001$, respectively). Nutritional supplement was more frequently prescribed in this last group $(\mathrm{P}<0.001)$.

At the end of follow-up, $84.3 \%$ of HD patients were dialyzed with an arterial venous fistula and $15.7 \%$ with a central venous catheter (CVC). There was no relationship between the type of vascular access and the nutritional status (CVC 15.4 vs $15.9 \%$; $\mathrm{P}=0.925$ in subjects with normal nutritional status and in those having 1 or more nutritional markers, respectively).

Additional file 1: Table S3 presents the IDWG according to the presence/absence of the nutritional markers. The IDWG at the start of the study and at the end of follow-up were significantly lower in presence of nutritional markers than in their absence, except for serum albumin $\leq 38 \mathrm{~g} / \mathrm{L}$. 
Additional file 1: Table S4 presents the adjusted HR (95\% CI) of death for PEW markers and for PEW status. Both models were adjusted for the following parameters: age $\geq 60$ years, gender, dialysis vintage $\geq 5$ years, diabetes, pre existing CVD, CRP $>5 \mathrm{mg} / \mathrm{L}$.

Concerning the models including the four PEW markers (model 1): the multivariate Cox regression showed, significant associations between age $\geq 60$ years $(P=0.049)$, low BMI $(\mathrm{P}=0.034)$, low serum albumin $(\mathrm{P}=0.001)$ and mortality. The association was nearly significant for low serum creatinine $(\mathrm{P}=0.051)$ but not significant for gender, diabetes, CRP $>5 \mathrm{mg} / \mathrm{L}$ and low protein intake.

Concerning the model including the PEW status (model 2): significant associations were noted between diabetes $(\mathrm{P}=0.034)$, moderate PEW $(\mathrm{P}=0.021)$, severe PEW $(P=0.001)$ and mortality. The association was nearly significant for age $(P=0.062)$ and $\mathrm{CRP} \geq 5 \mathrm{mg} / \mathrm{L}(\mathrm{P}=0.081)$ but not significant for gender, pre existing CVD and slight wasting.

The mean survival time [95 \% confidence interval $(\mathrm{CI})]$ was $31.6(30.2,32.9)$ months in the overall study population. This survival time was, respectively $23.5(17.6,29.5)$ months in patients who had a severe wasting; $30.5(27.7,32.3)$ months in those who had a moderate wasting; and $32.5(30.3,34.6)$ months in those who had a slight wasting; and 34.2 $(32.6,35.8)$ months in those who had a normal nutritional status. These times were significantly different between the four groups $(\mathrm{P}<0.001$, log-rank test). There was no statistical significant difference in survival between patients with slight wasting and those with normal nutritional status $(\mathrm{P}=0.18, \log$-rank test). The survival curves according to PEW status are shown in Fig. 1.

Since cardiovascular disease, diabetes mellitus and inflammation contribute to the high death rate in HD patients, we evaluated the potential additive effects of these co morbid factors on severe wasting (Fig. 2). These factors are all additives in predicting death in our HD patients but, diabetes appears as the strongest predictive factor of death in association with severe wasting. In comparing to patients without severe wasting and without diabetes, patients who had these both factors exhibited a HR of death of 7.76

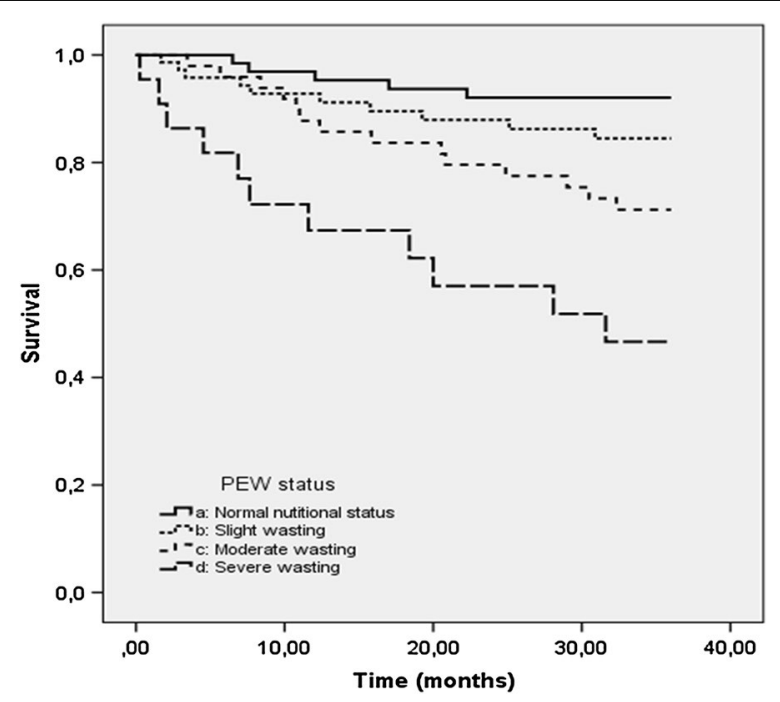

Fig. 1 Survival curves according to protein-energy wasting status $(P<0.001$, log-rank test) 


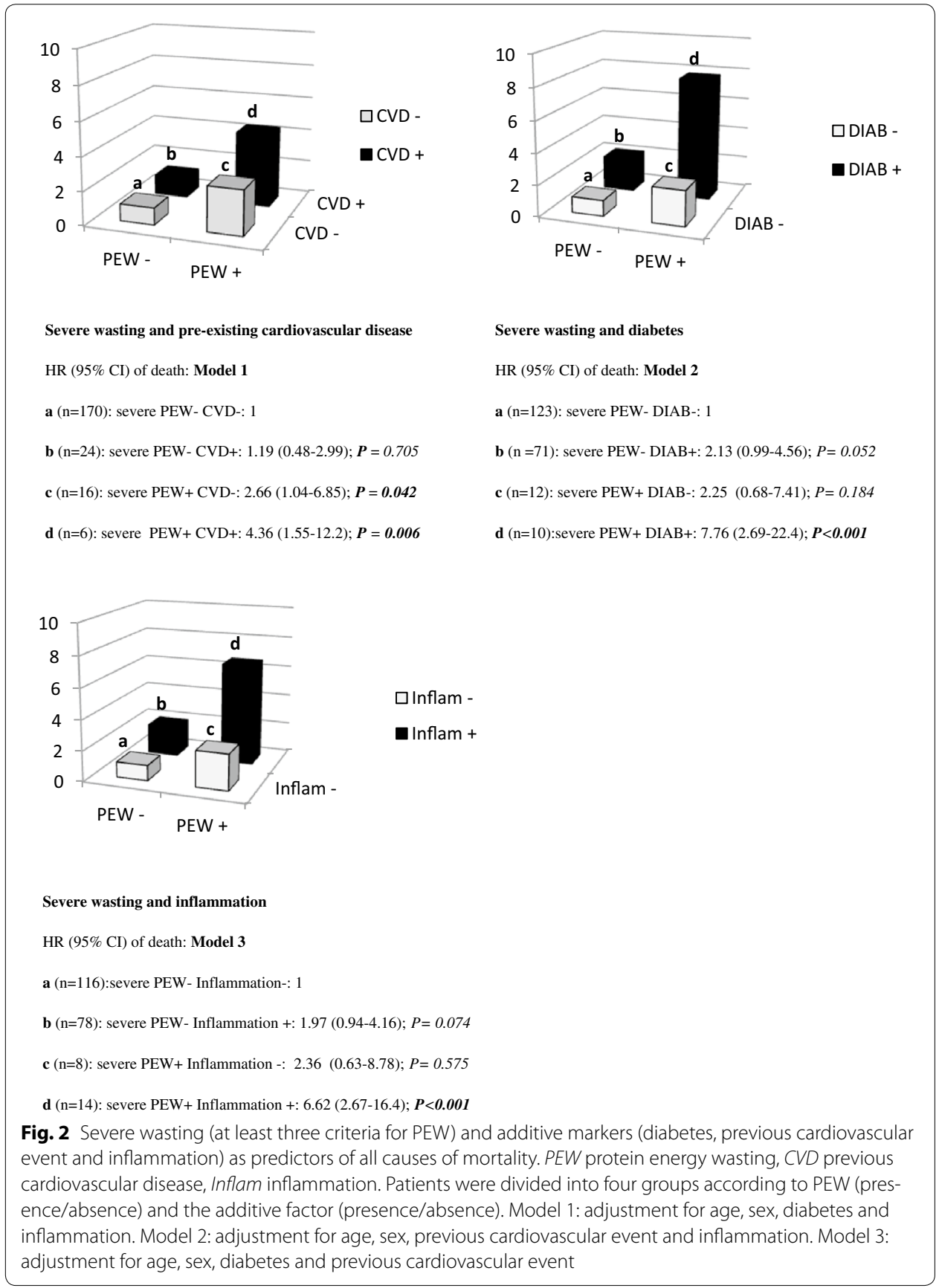

$(\mathrm{P}<0.001)$ whereas this HR was $2.25(\mathrm{P}<0.184)$ for patients having a severe wasting but no diabetes and $2.13(\mathrm{P}<0.052)$ for those having diabetes but no severe wasting.

\section{Discussion}

In this first study examining mortality according to nutritional status in a cohort of 216 Afro-Caribbean MHD patients who were followed for up to 3 years, we found that a lower BMI and lower serum albumin levels predicted worst survival. We also found a strong association between severe wasting status (three or more PEW criteria) and 
mortality. Pre existing cardiovascular disease, diabetes and inflammation incremented the risk of death associated with severe wasting, showing the contribution of all these factors to the high morbidity and mortality in patients with end-stage renal disease.

The nutritional and metabolic derangements observed in advanced chronic kidney disease cannot be attributed to any one single factor but, a common feature is the high rate of protein degradation (Marcelli et al. 2015). In the present study, we used four parameters among the established categories proposed by the International Society of Renal Nutrition and Metabolism to identify PEW (Fouque et al. 2008). Body mass index $\leq 23 \mathrm{~kg} / \mathrm{m}^{2}$, serum albumin $\leq 38 \mathrm{~g} / \mathrm{L}, \mathrm{SCr} \leq 25$ th percentile $\left(\mu \mathrm{mol} / \mathrm{L} / \mathrm{m}^{2}\right)$ and $\mathrm{nPCR}$ $\leq 0.8 \mathrm{~g} / \mathrm{kg} /$ day were the selected criteria. Excepted daily protein intake, all these parameters were significantly lower, at baseline, in patients who died during the study period.

The frequency of weight loss at baseline ( $5 \%$ over 3 months) was higher in patients who died than in the others $(22.5$ vs $4 \%, \mathrm{P}<0.001)$. According to the expert panel, a weight loss of $5 \%$ over 3 months might also be considered an indicator of PEW (Fouque et al. 2008). In addition our patients having a BMI $\leq 23 \mathrm{~kg} / \mathrm{m}^{2}$ had a HR of death about 2 time higher than the others. By contrast to the general population, overweight is paradoxically associated with improve survival in MHD patients, at least in the short term (Park et al. 2013). While obesity provides some protection against malnutrition, a low BMI should be in part the reflect of undernutrition.

Among the four criteria selected for the diagnosis of PEW, a low serum albumin concentration was the strongest predictor of death in our study. Several studies demonstrated the relationship between this criteria and outcome (Lowrie and Lew 1990; Owen et al. 1993). Serum albumin is an indicator of visceral proteins stores and is affected by protein intake but also by several factors including inflammation and other co morbidities (Kaysen 1998). Some authors in a previous study reported that patients with a serum albumin level below $35 \mathrm{~g} / \mathrm{L}$ had a relative mortality risk of 4 (Lowrie et al. 1995). This relative risk was 3.49 for serum albumin levels below $38 \mathrm{~g} / \mathrm{L}$ in our study population.

Serum creatinine is considered as a surrogate of muscle mass, especially in HD patients without residual renal function (Kalantar-Zadeh et al. 2012) and all patients in our study had no residual renal function. In a previous study among HD patients, creatinine levels below $8.0 \mathrm{mg} / \mathrm{dL}(704 \mu \mathrm{mol} / \mathrm{L})$ predicted higher mortality than those above $10 \mathrm{mg} / \mathrm{dL}$ $(880 \mu \mathrm{mol} / \mathrm{L})$ (Kalantar-Zadeh et al. 2010). Since there is no recognized threshold for low creatinine levels we chose in our study the 25th percentile of the whole value corresponding to $818 \mu \mathrm{mol} / \mathrm{L}(9.3 \mathrm{mg} / \mathrm{dL})$. Patients who died during the study period had lower baseline creatinine levels than the others. Those who had Scr below $818 \mu \mathrm{mol} / \mathrm{L}$ had a hazard ratio of death two time higher than those with $\mathrm{SCr}$ above this threshold. It was reported that individuals of African ancestry have higher measures of muscle and lean mass with higher levels of SCr than whites (Noori et al. 2011) probably in relation with higher protein intake.

The mean daily protein intake at baseline was higher than $1 \mathrm{~g} / \mathrm{kg} /$ day for our patient without significant difference in both groups. Protein catabolic rate below $1 \mathrm{~g} / \mathrm{kg} / \mathrm{day}$ was previously associated with increase morbidity and mortality (Acchiardo et al. 1983) and a minimal protein intake of $1.1 \mathrm{~g} / \mathrm{kg} /$ day is recommended (Fouque et al. 2007). But, the criteria for protein intake in the nomenclature for PEW corresponded to values below $0.8 \mathrm{~g} / \mathrm{kg} /$ day that was not associated with the risk of death in our study. 
The IDWG was found significantly lower in presence of the nutritional markers than in their absence, except for serum albumin levels $\leq 38 \mathrm{~g} / \mathrm{L}$. IDWG is a surrogate of patient's fluid and sodium intake but may also be an index of good appetite and nutritional status. A strong association between IDWG and nutritional markers has been reported with a potential risk of malnutrition in HD patients if the weight gain is low (Lopez-Gomez et al. 2005; Sezer et al. 2002) Sezer SRen Fail. Our results indeed show that subjects with insufficient protein intake (nPCR $\leq 0.8 \mathrm{~g} / \mathrm{kg} /$ day) or with low BMI had lower IDWG than the others which argues for a probable better nutrition in HD patients with high IDWG.

Patients in MHD suffer from multiple traditional or non traditional risk factors that are associated with mortality, such as diabetes, cardio vascular disease and inflammation. The Cox proportional hazard modelling (Fig. 2) showed that these three comorbidities evaluated were all additives in predicting mortality in presence of a severe wasting. In fact, for the association of each risk factor and severe wasting, the HR of death was higher than the addition of HR of the single factors. Diabetes mellitus (DM) is the leading cause of end-stage renal diseases in Guadeloupe (Foucan et al. 2000) as in many countries and appears, in the present study, as the strongest predictive factor of death in association with severe wasting.

Although the main cause of death was cardiovascular disease, the predictive value of diabetes was higher than that of pre-existing cardiovascular disease. A possible explanation is that diabetic condition is associated with several abnormalities such as inflammation, oxidative stress (Basta et al. 2004; Nath et al. 2013) prothrombogenic factors (Kirpichnikov and Sowers 2001), accelerated atherosclerosis (Foley and Parfrey 1998) that lead to cardiovascular complications and poor prognosis in HD patients. In fact, as previously reported (Racki et al. 2007), preexisting CVD were more prevalent in our MHD diabetic patients than in non diabetics. Inflammation is known as an important contributor to PEW in ESRD patients since pro-inflammatory cytokines stimulate protein catabolism (Bistrian et al. 1992), reduce albumin synthesis and contribute to anorexia (Plata-Salaman 1998). Protein energy wasting is known to be frequent in diabetic dialysis patients (Malgorzewicz et al. 2004) and to interact with inflammation and CVD (de Mutsert et al. 2008). Finally, all these factors contribute to the high death rate in MHD patients.

Our study has some limitations including the fact that the findings are limited to a relatively small number of patients. In addition, data were obtained from a prevalent cohort and potential variations of the criteria during the study period were not taken into account. Another limitation was that, we used a low BMI as one of the criteria for PEW. But, lean body mass and fat mass were not measured whereas it was previously suggested that their influence on survival are different (Beddhu et al. 2003; Noori et al. 2010).

One strength of our study was that the potential confounding effect of residual renal function was excluded because all patients in the present study had no residual renal function and in this situation higher creatinine levels relate to larger muscle mass and lower mortality (Park et al. 2013; Kalantar-Zadeh et al. 2010). There was also no bias in relation with type of dialysis or dialysis membrane since dialysis modalities were identical for all the subjects. In addition the data were obtained in a homogenous ethnic group 
of patients and this is of importance since measures of serum creatinine and other nutritional markers may vary according to ethnics groups.

\section{Conclusion}

In MHD patients, survival decreases with the increasing number of criteria for PEW and an additional deleterious effect on survival related to severe wasting was observed in patients with diabetes or cardiovascular disease or inflammation. The nomenclature and diagnostic criteria for PEW proposed by the International Society of Renal Nutrition and Metabolism predicts mortality in our Afro-Caribbean MHD patients and could help to identify patients at risk of severe wasting to provide them adequate nutritional support. However, our results highlight the need to implement and evaluate prevention strategies and management of malnutrition in MHD patients.

\section{Additional file}

Additional file 1: Table S1. Baseline demographic, clinical, and laboratory parameters in 216 maintenance hemodialysis patients at the start of the 3-year cohort study. Table S2. Baseline nutritional markers values and nutritional status (categorical) in 216 maintenance hemodialysis patients at the start of the 3-year cohort study. Table S3. Interdialytic weight gain according to nutritional status and nutritional markers in 216 hemodialysis patients. Table S4. Multivariate Cox proportional hazard models and death hazard ratios of 3-year mortality according to PEW markers and PEW status in 216 hemodialysis patients.

\section{Authors' contributions}

JD and HM participated in the conception, the design of the work, the interpretation of data, the drafting and revising of the article. LF participated in the conception, the design of the work, the interpretation of data, the drafting and revising of the article and performed the statistical analysis. FVC, LL and CA provided intellectual content of critical importance to the work and helped to draft the manuscript. All authors read and approved the final manuscript.

\section{Author details}

${ }^{1}$ Centre de dialyse AUDRA, Hôpital RICOU, Pointe-À-Pitre, Guadeloupe, France. ${ }^{2}$ Département de Santé Publique, Equipe de recherche Epidémiologie Clinique et Médecine ECM/LAMIA, EA 4540, Centre Hospitalier Universitaire, Université des Antilles et de la Guyane, CHU de Pointe-à-Pitre, 97159 Pointe-à-Pitre, Guadeloupe, France. ${ }^{3}$ Service de Néphrologie, Centre Hospitalier Universitaire, Pointe-à-Pitre, Guadeloupe, France.

\section{Acknowledgements}

We would like to acknowledge the nurses and the physicians of the AUDRA hemodialysis centre and all individuals who participated in this study.

\section{Compliance with ethical guidelines}

Competing interests

The authors declare that they have no competing interests.

\section{Informed consent}

The authors reported the results of the annual checkup and follow-up of the HD patients. No additional measurement was performed. So, the informed consent was not requested.

Research involving Human Participants

Received: 23 April 2015 Accepted: 18 August 2015

Published online: 26 August 2015

\section{References}

Acchiardo SR, Moore LW, Latour PA (1983) Malnutrition as the main factor in morbidity and mortality of hemodialysis patients. Kidney Int Suppl 16:S199-S203

Aparicio M, Cano N, Chauveau P et al (1999) Nutritional status of haemodialysis patients: a French national cooperative study. French Study Group for Nutrition in Dialysis. Nephrol Dial Transplant B14:1679-1686

Basta G, Schmidt AM, De Caterina R (2004) Advanced glycation end products and vascular inflammation: implications for accelerated atherosclerosis in diabetes. Cardiovasc Res 63:582-592

Beddhu S, Pappas LM, Ramkumar N, Samore M (2003) Effects of body size and body composition on survival in hemodialysis patients. J Am Soc Nephrol 14:2366-2372 
Bistrian BR, Schwartz J, Istfan NW (1992) Cytokines, muscle proteolysis, and the catabolic response to infection and inflammation. Proc Soc Exp Biol Med 200:220-223

Briancon S, Lange C, Thibon P, Jacquelinet C, Stengel B (2011) The incidence of ESRD in 2011. Nephrol Ther Suppl 1:S19-S37

Daugirdas JT (1989) The post: pre-dialysis plasma urea nitrogen ratio to estimate K.t/N and NPCR: mathematical modeling. Int J Artif Organs 12:411-419

de Mutsert R, Grootendorst DC, Axelsson J, Boeschoten EW, Krediet RT, Dekker FW (2008) Excess mortality due to interaction between protein-energy wasting, inflammation and cardiovascular disease in chronic dialysis patients. Nephrol Dial Transplant 23:2957-2964

Foley RN, Parfrey PS (1998) Cardiac disease in the diabetic dialysis patient. Nephrol Dial Transplant 13:1112-1113

Foucan L, Merault H, Deloumeaux J et al (2000) Survival analysis of diabetic patients on dialysis in Guadeloupe. Diabetes Metab 26:307-313

Foucan L, Ducros J, Merault H (2012) Vitamin D status in dark-skinned patients undergoing hemodialysis in a continually sunny country. J Nephrol 25:983-988

Fouque D, Vennegoor M, ter Wee P, et al. EBPG quideline on nutrition. Nephrol Dial Transplant. 2007;22 Suppl 2:ii45-87

Fouque D, Kalantar-Zadeh K, Kopple J et al (2008) A proposed nomenclature and diagnostic criteria for protein-energy wasting in acute and chronic kidney disease. Kidney Int 73:391-398

Gallagher D, Visser M, De Meersman RE et al (1985) Appendicular skeletal muscle mass: effects of age, gender, and ethnicity. J Appl Physiol 1997(83):229-239

Goodkin DA, Young EW, Kurokawa K, Prutz KG, Levin NW (2004) Mortality among hemodialysis patients in Europe, Japan, and the United States: case-mix effects. Am J Kidney Dis 44(5 Suppl 2):16-21

Kalantar-Zadeh K, Streja E, Kovesdy CP et al (2010) The obesity paradox and mortality associated with surrogates of body size and muscle mass in patients receiving hemodialysis. Mayo Clin Proc 85:991-1001

Kalantar-Zadeh K, Streja E, Molnar MZ et al (2012) Mortality prediction by surrogates of body composition: an examination of the obesity paradox in hemodialysis patients using composite ranking score analysis. Am J Epidemiol 175:793-803

Kaysen GA (1998) Biological basis of hypoalbuminemia in ESRD. J Am Soc Nephrol 9:2368-2376

Kirpichnikov D, Sowers JR (2001) Diabetes mellitus and diabetes-associated vascular disease. Trends Endocrinol Metab 12:225-230

Kovesdy CP, Kalantar-Zadeh K (2009) Why is protein-energy wasting associated with mortality in chronic kidney disease? Semin Nephrol 29:3-14

Kramer H, Palmas W, Kestenbaum B et al (2008) Chronic kidney disease prevalence estimates among racial/ethnic groups: the Multi-Ethnic Study of Atherosclerosis. Clin J Am Soc Nephrol 3:1391-1397

Lopez-Gomez JM, Villaverde M, Jofre R, Rodriguez-Benitez P, Perez-Garcia R. Interdialytic weight gain as a marker of blood pressure, nutrition, and survival in hemodialysis patients. Kidney Int Suppl. 2005:563-68

Lowrie EG, Lew NL (1990) Death risk in hemodialysis patients: the predictive value of commonly measured variables and an evaluation of death rate differences between facilities. Am J Kidney Dis 15:458-482

Lowrie EG, Huang WH, Lew NL (1995) Death risk predictors among peritoneal dialysis and hemodialysis patients: a preliminary comparison. Am J Kidney Dis 26:220-228

Malgorzewicz S, Lichodziejewska-Niemierko M, Rutkowski B, Lysiak-Szydlowska W (2004) Nutritional status and oxidative processes in diabetic and nondiabetic peritoneal dialysis patients. J Ren Nutr 14:242-247

Marcelli D, Wabel P, Wieskotten S et al (2015) Physical methods for evaluating the nutrition status of hemodialysis patients. J Nephrol [Epub ahead of print]

Moreau-Gaudry X, Jean G, Genet L et al (2014) A simple protein-energy wasting score predicts survival in maintenance hemodialysis patients. J Ren Nutr 24:395-400

Nath I, Nath CK, Baruah M, Pathak M, Banerjee R, Goyal S (2013) A study of inflammatory status in nephropathy patients with history of Type-II diabetes mellitus undergoing haemodialysis. J Clin Diagn Res 7:2143-2145

Noori N, Kovesdy CP, Dukkipati R et al (2010) Survival predictability of lean and fat mass in men and women undergoing maintenance hemodialysis. Am J Clin Nutr 92:1060-1070

Noori N, Kovesdy CP, Dukkipati R et al (2011) Racial and ethnic differences in mortality of hemodialysis patients: role of dietary and nutritional status and inflammation. Am J Nephrol 33:157-167

Owen WF Jr, Lew NL, Liu Y, Lowrie EG, Lazarus JM (1993) The urea reduction ratio and serum albumin concentration as predictors of mortality in patients undergoing hemodialysis. N Engl J Med 329:1001-1006

Park J, Jin DC, Molnar MZ et al (2013) Mortality predictability of body size and muscle mass surrogates in Asian vs white and African American hemodialysis patients. Mayo Clin Proc 88:479-486

Plata-Salaman CR (1998) Cytokines and anorexia: a brief overview. Semin Oncol 25(1 Suppl 1):64-72

Racki S, Zaputovic L, Vujicic B, Crncevic-Orlic Z, Dvornik S, Mavric Z (2007) Comparison of survival between diabetic and non-diabetic patients on maintenance hemodialysis: a single-centre experience. Diabetes Res Clin Pract 75:169-175

Sezer S, Ozdemir FN, Arat Z, Perim O, Turan M, Haberal M (2002) The association of interdialytic weight gain with nutritional parameters and mortality risk in hemodialysis patients. Ren Fail 24:37-48

Streja E, Kovesdy CP, Molnar MZ et al (2011) Role of nutritional status and inflammation in higher survival of African American and Hispanic hemodialysis patients. Am J Kidney Dis 57:883-893 